\title{
PROSPECTIVE, OPEN, NON-RANDOMISED COMPARATIVE STUDY TO ASSESS EFFICACY OF 0.5\% TIMOLOL MALEATE EYE DROP WITH COMBINATION TREATMENT OF 2\% DORZOLAMIDE AND 0.5\% TIMOLOL MALEATE EYE DROPS IN PATIENTS WITH PRIMARY OPEN ANGLE GLAUCOMA
}

\author{
Sathish C. Shitole ${ }^{1}$ S. S. Deshmukh²
}

${ }^{1}$ Assistant Professor, Department of Ophthalmology, RCSM Government Medical College, Kolhapur, Maharashtra. ${ }^{2}$ Associate Professor, Department of Ophthalmology, BJMC, Pune.

\section{ABSTRACT}

\section{BACKGROUND}

Glaucoma is among the leading causes of blindness in the developing world and a major health problem in the developed world. The goal of glaucoma treatment is to preserve good visual function for patient's lifetime. This is accomplished by lowering the IOP to a level that will stop or at least slow the progression of optic nerve damage and its consequent visual field loss.

This study is a prospective, open, non-randomised comparative study to assess efficacy of $0.5 \%$ Timolol maleate eye drop with combination treatment of $2 \%$ Dorzolamide and $0.5 \%$ Timolol maleate eye drops in patients with primary open angle glaucoma.

\section{MATERIALS AND METHODS}

60 patients were enrolled after informed and written consent as per inclusion and exclusion criteria. Current medical and ophthalmic history and diagnosis were noted during the first visit. Patients were assigned to receive Timolol or the combination of Dorzolamide and Timolol using a 1:1 allocation. Thereafter, patients were advised to self-instil one drop of timolol twice daily or one drop of the combination twice daily according to the group they had been allotted to. After enrolment into the study followup was done after 2 weeks, 4 weeks and 6 weeks. To avoid the effect of diurnal variation, it was taken care to note the IOP between 11 a.m. - 1 p.m. The primary efficacy endpoint was the change from baseline of intraocular tension. Statistical tests were used to analyse data that were paired ' $t$ ' test and unpaired ' $\mathrm{t}$ ' test.

\section{RESULTS}

The mean age of patients of timolol group was $53.96 \pm 5.23$ years and that of dorzolamide + timolol was $53.46 \pm 5.28$ years. In all two Timolol and Dorzolamide + Timolol groups, $50 \%$ patients were males and $50 \%$ patients were females. Number of cases subjected to statistical analysis were 27 in timolol group and 28 in Dorzolamide + timolol group. The mean baseline intraocular pressure in timolol group was $25.27 \pm 1.22 \mathrm{mmHg}$, while in Dorzolamide + timolol group was $25.50 \pm 1.28 \mathrm{mmHg}$. Values of mean reduction in IOP were compared between Dorzolamide + timolol with timolol. It was found to be statistically significant (p $<0.05)$ at 2 weeks and highly significant $(0.001)$ at 6 weeks.

\section{CONCLUSION}

When efficacy of fixed combination of timolol and Dorzolamide was compared with timolol drugs used, we found that combination of timolol and Dorzolamide was more effective in reducing IOP as compared to the individual drugs used alone.

\section{KEYWORDS}

Intraocular Pressure, Beta Blocker Drugs, Carbonic Anhydrase Inhibitors.

HOW TO CITE THIS ARTICLE: Shitole SC, Deshmukh SS. Prospective, open, non-randomised comparative study to assess efficacy of $0.5 \%$ timolol maleate eye drop with combination treatment of $2 \%$ dorzolamide and $0.5 \%$ timolol maleate eye drops in patients with primary open angle glaucoma. J. Evolution Med. Dent. Sci. 2017;6(73):5248-5252, DOI: 10.14260/Jemds/2017/1139

\begin{abstract}
BACKGROUND
Glaucoma is among the leading causes of blindness in the developing world and a major health problem in the developed world.(1) Primary open angle glaucoma is the most common form of glaucoma. It is a chronic progressive disease, if left untreated leads to anterior optic neuropathy accompanied by a characteristic cupping and atrophy of the optic disc and visual field loss. Elevated 'Intraocular Pressure' (IOP) is the most important known risk factor for the progression of visual field loss in patients with glaucoma.(2)
\end{abstract}

Financial or Other, Competing Interest: None.

Submission 14-08-2017, Peer Review 30-08-2017,

Acceptance 01-09-2017, Published 11-09-2017.

Corresponding Author:

Dr. S. S. Deshmukh,

Associate Professor

Department of Ophthalmology,

BJMC, Pune.

E-mail: drsatish.shitole@gmail.com

DOI: $10.14260 /$ jemds $/ 2017 / 1139$

\section{(c) $(\mathrm{F})$}

The goal of glaucoma treatment is to preserve good visual function for patient's lifetime. This is accomplished by lowering the IOP to a level that will stop or at least slow the progression of optic nerve damage and its consequent visual field loss.(3-6) Medical therapy has been the mainstay of initial glaucoma treatment for over a century. Within the last two decades several new, effective and well-tolerated glaucoma medications have been introduced. Currently available drugs for the treatment of glaucoma include $\beta$-blockers, $\alpha$ adrenergic agonists, prostaglandin analogues, carbonic anhydrase inhibitors and miotics.

These IOP lowering medications allow many patients to achieve their IOP lowering goals with a single medication, $(7,8)$ but not all patients can use these drugs. Despite the substantial IOP lowering possible with monotherapy, many patients may need to use two or more medications to reach a target IOP sufficiently low to halt further visual deterioration.(3,9) In the Ocular Hypertension Treatment Study(3) by year 5 , almost $40 \%$ of the patients required 2 or more medications to achieve their target IOP. In the medical 
arm of the Collaborative Initial Glaucoma Treatment Study,(9) more than $75 \%$ of the patients required 2 or more medications after 2 years. Two commonly used classes of IOP-lowering drugs are the - adrenergic antagonists $\beta$. blockers) and carbonic anhydrase inhibitors. The nonselective $\beta$-blocker timolol lowers IOP by decreasing aqueous humor production ${ }^{(10)}$ and the carbonic anhydrase inhibitors dorzolamide lowers IOP by decreasing aqueous humor production.(11) These 2 drugs are widely used and each was shown to be effective as adjunctive therapy with other classes of IOP-lowering medications.(12-14) For patients who require more than 1 medication for IOP control, fixed combinations of drugs are more convenient than the concomitant use of the separate components and may improve compliance. Use of a combination product can also decrease the patient's daily ocular exposure to preservatives. The purpose of this study was to compare the efficacy and safety of a fixed combination of $2 \%$ dorzolamide and $0.5 \%$ timolol maleate with that of either component administered as monotherapy.

\section{Aim and Objective}

To study the efficacy of combination of 'Timolol and Dorzolamide' and Timolol.

\section{MATERIALS AND METHODS}

The study was conducted in outpatient Department of Ophthalmology, RCSM Government Medical College, Kolhapur in accordance with the principles of Declaration of Helsinki between period of April 2016 and March 2017.

\section{Study Design}

This was a prospective, open, non-randomised, comparative controlled clinical trial. Total 60 patients were enrolled into the study as per selection criteria.

\section{Inclusion Criteria}

1. Patients of either sex with 18 years of age or older.

2. Patients of unilateral primary open angle glaucoma with IOP of $22 \mathrm{mmHg}$ and above by Goldmann applanation tonometry, open anterior chamber angle, characteristic optic disc cupping and/or visual field loss.

3. Snellen's visual acuity of $6 / 60$ or better.

4. Patients who have given informed consent.

5. Patients of newly diagnosed primary open angle glaucoma or those previously using topical antiglaucoma therapy, who discontinued therapy voluntarily for 4 weeks or more.

\section{Exclusion Criteria}

1. Patients having anterior synechiae, clinically dry eye syndrome, active ocular infection, inflammation and significant ocular trauma.

2. Patients taking other systemic or ocular medications that could have substantial effect on intraocular pressure.

3. Patients of bronchial asthma or other reactive airway disease, severe heart failure, sinus bradycardia, hypotension and diabetes mellitus.
4. Patients with history of ocular surgery in last 3 months.

5. Patients with only one sighted eye.

6. Patients using contact lenses.

7. Patients with corneal abnormalities.

8. Patients with history of herpetic keratitis, corneal ulcer in last one year.

9. Female patients of child bearing age group not using medically approved contraceptives.

Patients were non-randomised to receive either timolol or dorzolamide + timolol fixed combination with 30 patients in each group.

Group A: Patients included in this group received timolol maleate $(0.5 \%)$ ophthalmic solution twice daily topically.

Group B: Patients included in this group received Dorzolamide (2\%) and timolol (0.5\%) fixed combination ophthalmic solution twice daily topically.

\section{Study Schedule and Plan}

The patients were enrolled after informed and written consent as per inclusion and exclusion criteria. Current medical and ophthalmic history and diagnosis were noted during the first visit. Patients were randomly assigned to receive Timolol or the combination of Dorzolamide and Timolol using a 1:1 allocation. Patients received their first dose of medication ( 1 drop in each eye) after all evaluations at the baseline visit.

Thereafter patients were advised to self-instil one drop of timolol twice daily or one drop of the combination twice daily according to the group they had been allotted to.

After enrolment into the study, followup was done after 2 weeks, 4 weeks and 6 weeks.

At each visit, thorough ocular examination of the patient including and intraocular pressure, visual acuity, direct ophthalmoscopy and slit lamp examination was performed. The intraocular pressure was recorded with Goldmann Applanation Tonometry. To avoid the effect of diurnal variation, it was taken care to note the IOP between 11 a.m. 1 p.m. The patient was explained to take care not to instil the drop just before coming for the followup. The patients who did not respond to the medication for 4 weeks were called as non-responders and referred to the ophthalmologist for further management.

The primary efficacy end point was the change from baseline of intraocular tension. Those patients who did not complete full 6 weeks therapy as per study regulations were not included for statistical analysis.

\section{Statistics}

Statistical tests used to analyse the data were paired ' $\mathrm{t}$ ' test and unpaired ' $\mathrm{t}$ ' test.

$P$ value $<0.05$ was taken as significant and ' $\mathrm{p}$ ' value $<0.001$ was taken as highly significant, while ' $p$ ' value $>0.05$ was considered as insignificant. 
RESULTS

\begin{tabular}{|c|c|c|c|c|}
\hline \multirow{2}{*}{ Parameters } & Timolol & $\begin{array}{c}\text { Dorzolamide } \\
\mathbf{n}=\mathbf{3 0}\end{array}$ & $\begin{array}{c}\text { P } \\
\text { N=30lol }\end{array}$ & value \\
\hline Age (yrs.) & $\begin{array}{c}\text { Mean } \pm \\
\text { S.D }\end{array}$ & $53.96 \pm 5.23$ & $53.46 \pm 5.28$ & $\mathrm{p}>0.05$ \\
\hline \multirow{2}{*}{ Sex } & Male & $15(50 \%)$ & $15(50 \%)$ & $\mathrm{p}>0.05$ \\
\cline { 2 - 5 } & Female & $15(50 \%)$ & $15(50 \%)$ & $\mathrm{p}>0.05$ \\
\hline $\begin{array}{c}\text { Patients } \\
\text { previously on } \\
\text { anti-glaucoma } \\
\text { therapy }\end{array}$ & $3(10 \%)$ & $4(13.33 \%)$ & \\
\hline \multicolumn{4}{|c|}{ Table 1. Demography of Patients } \\
\hline \multicolumn{5}{|c|}{} \\
\hline
\end{tabular}

As seen from above table, the mean age of patients of timolol group was $53.96 \pm 5.23$ years and that of dorzolamide + timolol was $53.46 \pm 5.28$ years.

In all two Timolol and Dorzolamide + Timolol groups, $50 \%$ patients were males and $50 \%$ patients were females.

In timolol group $10 \%$ and in Dorzolamide + timolol group, $13.33 \%$ patients had received antiglaucoma drugs before enrolment into the study, but had discontinued therapy voluntarily due to economic constraints or other reasons.

\begin{tabular}{|c|c|c|c|}
\hline $\begin{array}{c}\text { Sl. } \\
\text { No. }\end{array}$ & Parameters & Timolol & $\begin{array}{c}\text { Dorzolamide + } \\
\text { Timolol }\end{array}$ \\
\hline 1 & $\begin{array}{c}\text { Number of patients } \\
\text { enrolled for study }\end{array}$ & 30 & 30 \\
\hline 2 & Number of dropouts & 3 & 2 \\
\hline 3 & $\begin{array}{c}\text { Number of cases } \\
\text { analysed for efficacy }\end{array}$ & 27 & 28 \\
\hline 4 & $\begin{array}{c}\text { Reason for dropout: } \\
\text { Lost for followup }\end{array}$ & 3 & 2 \\
\hline \multicolumn{3}{|c|}{ Table 2. Details about Enrolment and Dropout } \\
\hline
\end{tabular}

Table no. 2 shows that in the beginning of the study, 30 patients were enrolled in each group after obtaining informed consent. During the study period, there were 3 dropouts in timolol group and 2 dropouts in Dorzolamide + timolol group. These dropouts were excluded from the study analysis, as they did not complete the study schedule. So, the number of cases subjected to statistical analysis were 27 in timolol group and 28 in the Dorzolamide + timolol group. The reason for dropouts was failure to report for followup.

\begin{tabular}{|c|c|c|c|c|}
\hline $\begin{array}{c}\text { Sl. } \\
\text { No. }\end{array}$ & Parameters & $\begin{array}{c}\text { Timolol } \\
\text { Mean } \pm \text { S.D }\end{array}$ & $\begin{array}{c}\text { Dorzolamide } \\
\text { + Timolol } \\
\text { Mean } \pm \text { S.D }\end{array}$ & $\begin{array}{c}\text { P } \\
\text { value }\end{array}$ \\
\hline 1 & $\begin{array}{c}\text { Mean } \\
\text { intraocular } \\
\text { pressure in } \\
\text { mmHg }\end{array}$ & $25.27 \pm 1.22$ & $25.50 \pm 1.28$ & $\mathrm{p}>0.05$ \\
\multicolumn{2}{|c|}{ Table 3. Baseline Clinical Characteristics of Patients } \\
\hline
\end{tabular}

The mean baseline intraocular pressure in timolol group was $25.27 \pm 1.22 \mathrm{mmHg}$, while in Dorzolamide + timolol group was $25.50 \pm 1.28 \mathrm{mmHg}$. When these groups were compared with each other, there was no significant difference between these groups ( $p>0.05)$.

\begin{tabular}{|c|c|c|}
\hline Sl. No. & Parameters & $\begin{array}{c}\text { Intraocular } \\
\text { Pressure in mmHg } \\
\text { Mean } \pm \text { S.D }\end{array}$ \\
\hline 1 & Baseline & $25.27 \pm 1.22$ \\
\hline 2 & After 2 weeks & $20.93 \pm 1.14$ \\
\hline 3 & After 4 weeks & $20.33 \pm 1.36$ \\
\hline 4 & After 6 weeks & $19.85 \pm 1.58$ \\
\hline \multicolumn{2}{|c|}{ Table 4. Effect of Timolol on Intraocular Pressure } \\
\hline
\end{tabular}

In timolol treated group, the mean intraocular pressure prior to treatment was $25.27 \pm 1.22 \mathrm{mmHg}$. After treatment, intraocular pressure reduced to $20.93 \pm 1.14 \mathrm{mmHg}, 20.33 \pm$ $1.36 \mathrm{mmHg}$ and $19.85 \pm 1.58 \mathrm{mmHg}$ at 2 weeks, 4 weeks and at 6 weeks respectively. The reduction in mean intraocular pressure was found to be statistically significant $(\mathrm{p}<0.05)$ at 2,4 and 6 weeks of therapy when compared with baseline readings.

\begin{tabular}{|c|c|c|}
\hline Sl. No. & Parameters & $\begin{array}{c}\text { Intraocular Pressure } \\
\text { in } \mathbf{~ m m H g} \\
\text { Mean } \pm \text { S.D }\end{array}$ \\
\hline 1 & Baseline & $25.50 \pm 1.28$ \\
\hline 2 & After 2 weeks & $19.96 \pm 1.23$ \\
\hline 3 & After 4 weeks & $19.25 \pm 1.58$ \\
\hline 4 & After 6 weeks & $18.14 \pm 2.16$ \\
\hline
\end{tabular}

Table 5. Effect of Dorzolamide + Timolol on Intraocular Pressure

In Dorzolamide + timolol treated group, the mean intraocular pressure prior to treatment was $25.50 \pm 1.28$ $\mathrm{mmHg}$. After treatment, intraocular pressure reduced to $19.96 \pm 1.23 \mathrm{mmHg}, 19.25 \pm 1.58 \mathrm{mmHg}$ and $18.14 \pm 2.16$ mmHg at 2 weeks, 4 weeks and at 6 weeks respectively. The reduction in mean intraocular pressure was found to be statistically significant $(p<0.05)$ at 2,4 and 6 weeks of therapy when compared with baseline readings.

\begin{tabular}{|c|c|c|c|}
\hline \multirow{2}{*}{ Sl. No. } & Parameters & \multicolumn{2}{|c|}{$\begin{array}{c}\text { Mean Reduction in Intraocular } \\
\text { Pressure from Baseline in mmHg } \\
\text { (Mean } \pm \text { S.D) }\end{array}$} \\
\cline { 3 - 4 } & & $\begin{array}{c}\text { Timolol } \\
\mathbf{N}=27\end{array}$ & $\begin{array}{c}\text { Dorzolamide + } \\
\text { Timolol } \\
\mathbf{N = 2 8}\end{array}$ \\
\hline 1 & After 2 weeks & $4.34 \pm 1.21$ & $5.54 \pm 1.87$ \\
\hline 2 & After 4 weeks & $4.94 \pm 1.24$ & $6.25 \pm 2.15$ \\
\hline 3 & After 6 weeks & $5.42 \pm 1.50$ & $7.36 \pm 2.58$ \\
\hline \multicolumn{2}{|c|}{ Table 6. Comparison between Mean Reduction in } \\
Intraocular Pressure from Baseline of Timolol and \\
Dorzolamide + Timolol
\end{tabular}

The mean reduction in intraocular pressure timolol and Dorzolamide + timolol group were $4.34 \pm 1.21 \mathrm{mmHg}$ and $5.54 \pm 1.87 \mathrm{mmHg}$ respectively at 2 weeks, $4.94 \pm 1.24 \mathrm{mmHg}$ and $6.25 \pm 2.15 \mathrm{mmHg}$ respectively at 4 weeks and $5.42 \pm$ $1.50 \mathrm{mmHg}$ and $7.36 \pm 2.58 \mathrm{mmHg}$ respectively at 6 weeks.

When values of mean reduction in IOP were compared between Dorzolamide + timolol with timolol. It was found to be statistically significant $(\mathrm{p}<0.05)$ at 2 weeks and highly significant (0.001) at 6 weeks.

\section{DISCUSSION}

Glaucoma is the leading cause of blindness in the developing world and a major health problem in the developed world.(1) Primary open angle glaucoma is the most common form of glaucoma. It is a chronic progressive disease, if left untreated leads to progressive increase in intraocular pressure, 
characteristic cupping and atrophy of the optic disc and visual field loss.

It has been evident that elevated intraocular pressure is the most important factor determining the outcome of glaucoma patient in terms of visual field changes.(2) Therefore, the drugs which lower intraocular pressure substantially are more effective in attenuating the neuropathic changes in optic disc and in preserving the vision. ${ }^{(3-6)}$

Timolol, a beta blocker, lowers IOP by blocking $\beta 2$ adrenergic receptors in the ciliary body, thereby suppressing the aqueous humor production. It is being used extensively worldwide as the first line agent for the treatment of primary open angle glaucoma (POAG) and elevated intraocular pressure (IOP).

Studies like Ocular Hypertension Treatment Study(3) and Collaborative Initial Glaucoma Treatment Study(9) have shown that $40 \%-70 \%$ patients on single IOP lowering drug require an additional drug after some time in the course of the disease to maintain IOP sufficiently low to prevent visual deterioration.

Dorzolamide carbonic anhydrase inhibitor topically lowers the intraocular pressure by reducing aqueous humor production from ciliary body.(11)

Thus, if the Dorzolamide is added to timolol monotherapy it may have an additive effect in lowering IOP and may help to maintain the IOP in lower range.(12-14)

Hence, use of combination of drugs in patients of glaucoma may be more effective in preventing continued visual field loss by maintaining the IOP at lower levels.

In this study we have evaluated the additive effect, if any of Dorzolamide (2\%) - timolol (0.5\%) combination over monotherapy with the individual components in the management of primary open angle glaucoma. We have also evaluated the safety and tolerability of the Dorzolamidetimolol combination and compared it with monotherapy with individual timolol components.

In the non-randomised study carried out by Harris et al(15) significantly reduced intraocular pressure from baseline 14.7 to $13.4 \mathrm{mmHg},(\mathrm{P}<.05)$ which is statistically significant. Thus, the results of our study are in congruence with these studies further supporting the additive IOP lowering effect of the dorzolamide-timolol fixed combination.

Data from the Early Manifest Glaucoma Trial(6) have shown that even $1 \mathrm{mmHg}$ of additional IOP lowering reduces the risk of glaucoma progression by $10 \%$. Thus, the additive effect of the fixed combination should prove beneficial regarding preserving the patient's vision for his lifetime.

Thus, based on the results of our studies and various other supporting studies, dorzolamide-timolol fixed combination proves to have an additive effect and is more effective and safe as the individual agents used alone for the treatment of primary open angle. $(13,14,15)$

Still long term studies are required to conclusively prove that the long-term outcome of the combination is actually better than monotherapy.

\section{CONCLUSION}

Timolol, a beta blocker and Dorzolamide carbonic anhydrase inhibitor decrease the increased IOP by different mechanisms. In the current study, we have evaluated the additive effect, if any of the fixed combination of timolol and Dorzolamide used topically in eye for treatment of primary open angle glaucoma.

When efficacy of fixed combination of timolol and Dorzolamide was compared with timolol drugs used, we found that combination of timolol and Dorzolamide was more effective in reducing IOP as compared to the individual drugs used alone.

\section{REFERENCES}

[1] Quigley HA. Number of people with glaucoma worldwide. Br J Ophthalmol 1996;80(5):389-93.

[2] Drake MV, Lierberman MF, Stamper R. BeckerShaffer`s diagnosis and therapy of glaucomas. $7^{\text {th }}$ edn. St Louis: Mosby Inc, 1999.

[3] Kass MA, Heuer DK, Higginbotham EJ, et al. The ocular hypertension treatment study: a randomized trial determines that topical ocular hypotensive medication delays or prevents the onset of primary open-angle glaucoma. Arch Ophthalmol 2002;120(6):701-13.

[4] Danias J, Podos SM. Comparison of glaucomatous progression between untreated patients with normaltension glaucoma and patients with therapeutically reduced intraocular pressures. The effectiveness of intraocular pressure reduction in the treatment of normal-tension glaucoma. Am J Ophthalmol 1999;127(5):623-5.

[5] AGIS Investigators. The advanced glaucoma intervention study (agis), 7: the relationship between control of intraocular pressure and visual field deterioration. Am J Ophthalmol 2000;130(4):429-40.

[6] Heijl A, Leske MC, Bengtsson B, et al. Reduction of intraocular pressure and glaucoma progression: results from the early manifest glaucoma trial. Arch Ophthalmol 2002;120(10):1268-79.

[7] Noecker RS, Dirks MS, Choplin NT, et al. A six-month randomized clinical trial comparing the intraocular pressure-lowering efficacy of bimatoprost and latanoprost in patients with ocular hypertension or glaucoma. Am J Ophthalmol 2003;135(1):55-63.

[8] Parrish RK, Palmberg P, Sheu WP, et al. A comparison of latanoprost, bimatoprost, and travoprost in patients with elevated intraocular pressure: a 12week, randomized, masked-evaluator multicenter study. Am J Ophthalmol 2003;135(5):688-703.

[9] Lichter PR, Musch DC, Gillespie BW, et al. Interim clinical outcomes in the collaborative initial glaucoma treatment study comparing initial treatment randomized to medications or surgery. Ophthalmology 2001;108(11):1943-53.

[10] Neufeld AH, Bartels SP, Liu JH. Laboratory and clinical studies on the mechanism of action of timolol. Surv Ophthalmol 1983;28(suppl):286-92. 


\section{Jemds.com}

[11] Becker B. Decrease in intraocular pressure in man by carbonic anhydrase inhibitor, diamox; a preliminary report. Am J Ophthalmol 1954;37(1):13-5.

[12] Zabriskie N, Netland PA. Comparison of brimonidine/latanoprost and timolol/dorzolamide: two randomized, double-masked, parallel clinical trials. Adv Ther 2003;20(2):92-100.

[13] Day DG, Schacknow PN, Wand M, et al. Timolol $0.5 \%$ /dorzolamide $2 \%$ fixed combination vs timolol maleate $0.5 \%$ and unoprostone $0.15 \%$ given twice daily to patients with primary open-angle glaucoma or ocular hypertension. Am J Ophthalmol 2003;135(2):138-43.

\section{Original Research Article}

[14] Sall KN, Greff LJ, Johnson-Pratt LR, et al. Dorzolamide/timolol combination versus concomitant administration of brimonidine and timolol. Ophthalmology 2003;110(3):615-24.

[15] Harris A, Jonescu-Cuypers CP, Kagemann L, et al. Effect of dorzolamide timolol combination versus timolol $0.5 \%$ on ocular bloodflow in patients with primary open-angle glaucoma. Am J Ophthalmol 2001;132(4):490-5. 